\title{
Peningkatkan Ketrampilan Motorik Kasar Siswa Down Syndrome melalui Senam Ceria
}

\author{
Tulus Sukma Al Wafi ${ }^{1}$, Sihkabuden ${ }^{2}$ \\ ${ }^{1}$ SLBN Dr. Rajiman Wedyodiningrat Ngawi \\ ${ }^{2}$ Universitas Negeri Malang \\ Email: wafisukma5@gmail.com
}

\begin{abstract}
Abstrak: Kurangnya ketrampilan motorik merupakan salah satu hambatan yang dimiliki oleh siswa down syndrome. Untuk meningkatkan ketrampilan motorik dapat dilakukan dengan senam ceria. Penelitian dan pengembangan ini bertujuan untuk mengetahui pemanfaatan video senam ceria terhadap ketrampilan motorik kasar siswa down syndrome. Jenis penelitian yang digunakan adalah penelitian pengembangan yang diadaptasi dari model pengembangan Arief S. Sadiman (2010). Terdapat 3 subjek validasi yaitu, (1) validasi ahli media yang menunjukkan presentase $94 \%$, (2) validasi ahli pembelajaran ABK yang memperoleh presentase $92 \%$, dan (3) ahli materi yang memperoleh presensate $87 \%$. Subjek uji coba dilakukan kepada 4 siswa down syndrome dengan diperoleh rata-rata ketuntasan adalah $100 \%$. Artinya adalah video senam ceria sangat layak dan sangat efektif sebagai media pembelajaran untuk meningkatkan ketrampilan motorik kasar siswa down syndrome. Diharapkan hasil penelitian ini dapat menjadi referensi baru dalam pengembangan media pembelajaran dan peningkatan ketrampilan motorik kasar.
\end{abstract}

Kata Kunci: ketrampilan motorik kasar, down syndrome, senam ceria

\begin{abstract}
The lack of motor skills is one of the student's obstacles with Down syndrome. To improve motor skills can be with "Senam Ceria". To know utilization of "Senam Ceria" video about gross motor skills of students with Down syndrome is the purpose of this research and development using Arief S. Sadiman (2010) development model. There are 3 validation subjects are, (1) media expert showed the precentage of $94 \%$, (2) ABK learning expert was obtaine of $92 \%$ and (3) a percentage of $87 \%$ was obtained from material expert. Subject trials conducted to 4 students with Down syndrome was obtaine an average achievement of $100 \%$. It means "Senam Ceria" video is very valid and effective as a learning media to improve gross motor skills of students with Down syndrome. It is expected that the results of this study can be a new reference in the development of learning media and improvement of crude motor skills.
\end{abstract}

Key Words: gross motor skill, down syndome, senam ceria

Pendidikan khusus adalah pendidikan bagi seorang siswa yang memiliki hambatan mental, emosional, fisik, sosial dan/atau memiliki potensi cerdas istimewa dan bakat istimewa (CIBI) sehingga mengalami tingkat kesulitan untuk mengikuti proses pembelajaran (UU No. 20 Tahun 2003 Pasal 32 Ayat 1). Siswa down syndrome adalah salah satu siswa berkebutuhan khusus yang memiliki hambatan mental, fisik, intelegensi dan kemampuan untuk kontrol motorik. Down syndrome adalah penyebab utama dari reterdasi mental, yang berarti lambat belajar dibandingkan kemampuan ratarata (Brill, 2007). Menurut Gleen Doman (ahli fisik dan terapi pendiri di Institute for The Achievement of Human Potential) dalam Kusumawati (2013) menyatakan bahwa anak down syndrome disebabkan oleh otak yang cidera. Otak adalah pusat utama koordinasi tubuh. Didalam otak, terdapat bagian otak yang dinamakan Lobus Frontalis sebagai area motorik yang berguna mengontrol kerja otot. Down Syndrome sangat berpengaruh terhadap tumbuh kembang anak, terutama tumbuh kembang motoriknya (Dekayati et.al , 2014). Anak atau siswa cacat mental ditandai dengan lemahnya kontrol motorik, kurang kemampuannya untuk berkoordinasi, tetapi dipihak lain bisa dilatih untuk mencapai kemampuan sampai ke titik normal (Kusumawati, 2013).

Ketrampilan motorik adalah kegiatan motorik yang memiliki derajat ketelitian yang tinggi, tetapi tujuannya adalah untuk menampilkan suatu suatu perbuatan yang khas atau menyelesaikan suatu tujuan tertentu (Abdurrahman, 2012). Kontrol motorik yang lemah dapat menyebabkan kesulitan belajar (Abdurrahman, 2012). Untuk menyelesaikan permasalahan tersebut, perlu adanya latihan agar terciptanya kotrol motorik yang bagus. Ketrampilan motorik yang pertama dilatih adalah ketrampilan motorik kasar, yang mempengaruhi adanya ketrampilan motorik halus. Keterampilan motorik kasar adalah keterampilan yang membutuhkan atau melibatkan otot besar, sedangkan motorik halus melibatkan gerakan-gerakan yang diatur secara halus (Santrok, Jhon W, 2007). Ketrampilan motorik kasar adalah koordinasi otot-otot dan saraf yang lebih besar, contohnya berjalan, berlari, merangkak dan makan (Olivia, 2009). Untuk melatih ketrampilan motorik kasar, dapat dilakukan dengan senam. 
Bagan 1. model pengembangan Arief S. Sadiman

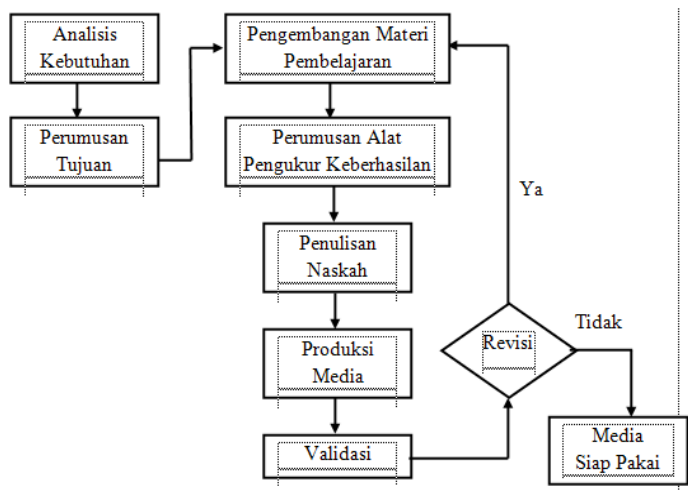

Senam merupakan aktivitas fisik yang dapat mengoptimalkan perkembangan anak (Mahendra, 2002). Senam merupakan latihan olah tubuh agar terbentuk daya tahan, kelincahan, kelentukan, koordinasi dan kontrol tubuh yang baik. Selain itu fungsi dari latihan senam ini sejalan dengan Pradipta (2017) Dalam rangka pencegahan permasalahan baru dan meningkatkan fungsi anggota gerak yang mengalami kekakuan. Hasil penelitian yang dilakukan oleh Nisnayeni (2012) menunjukkan bahwa adanya peningkatan perkembangan motorik kasar anak melalui senam irama setelah adanya tindakan pada siklus II. Selain itu terdapat hasil penelitian yang dilakukan oleh Yusmarni (2012) menyimpulkan bahwa dengan kegiatan senam fantasi dapat meningkatkan kemampuan motorik kasar pada anak di Taman Kanak-kanak. Kontrol motorik yang dimiliki siswa down syndrome masih lemah, sehingga perlu dikembangkan media pembelajaran yang dapat membantu meningkatkan kontrol motorik pada siswa down syndrome.

Untuk mengatasi permasalahan motorik pada siswa down syndrome, peneliti tertarik melakukan upaya peningkatan ketrampilan motorik kasar siswa down syndrome dengan mengembangkan media pembelajaran berupa senam ceria. Senam ceria merupakan adaptasi dari senam irama. Senam irama adalah bentuk-bentuk gerakan senam yang merupakan berbagai bentuk gerakan dengan irama yang mengiringinya, misalnya seperti irama tepukan, ketukan, tambore, nyanyian, musik dan sebagainya" (Sudarsini, 2013). Senam ceria adalah senam yang dibuat dengan iringan musik dan hitungan serta model/ instrktur senam adalah seorang badut. Tujuan dari penelitian dan pengembangan ini adalah melatih dan meningkatkan ketrampilan motorik kasar pada siswa down syndrome.

\section{METODE}

Prosedur pelaksanaannya melalui beberapa tahap, yaitu: (1) analisis kebutuhan dan karakteristik siswa, (2) perumusan tujuan, (3) pengembangan materi pembelajaran, (4) perumusan alat pengukur keberhasilan, (5) penulisan naskah, (6) produksi media, (7) validasi, (8) revisi dan (9) media siap pakai. Prosedur yang dilakukan pada penelitian dan pengembangan ini adalah sebagai berikut. Pertama, analisis kebutuhan dan karakteristik siswa dengan melakukan observasi secara langsung kemudian melakukan wawancara dan pemberian angket kepada guru olahraga yang bertujuan untuk mengetahui karakteristik dan permasalahan yang dialami siswa pada sekolah tersebut. Kedua, perumusan tujuan berdasarkan kompetensi inti dan kompetensi dasar. Dengan adanya kompetensi inti dan kompetensi dasar, senam irama yang dikembangkan menjadi senam ceria dapat meningkatkan ketrampilan motorik kasar siswa down syndrome dan dapat dinyatakan lulus berdasar kriteria Standar Ketuntasan Minimal (SKM). Ketiga, pengembangan materi pembelajaran yang dilakukan oleh peneliti bekerja sama dengan guru olahraga di sekolah untuk menyusun gerakan dalam video senam, yang terdiri dari gerakan pemanasan, gerakan inti dan gerakan pendinginan. Keempat, perumusan alat pengukur keberhasilan menggunakan tehnik pengumpulan data berupa tes. Alat pengukur keberhasilan disusun berdasarkan tingkat kemampuan siswa down syndrome dalam mengikuti gerakan senam. Kelima, penulisan naskah melalui beberapa kegiatan yaitu: (1) membuat sinopsis, (2) membuat treatment, (3) membuat naskah dan (4) membuat storyboard. Keenam, adalah produksi media yaitu menggabungkan materi yang sudah disiapkan sesuai dengan naskah kemudian dibuat menjadi video pembelajaran yang dikemas dalam bentuk CD/DVD yang belum divalidasi. Ketujuh, adalah validasi yang dilakukan dengan pemberian angket, sebagai alat pengumpul data yang akan digunakan dalam menetapkan kelayakan produk yang digunakan, kemudian dilanjutkan dengan uji coba.validasi diberikan kepada 3 ahli, yaitu: (1) ahli media, yang berkompeten dalam bidang media pembelajaran, (2) ahli pembelajaran ABK, yang berkompeten dalam bidang Pendidikan Luar Biasa dan Pendidikan Jasmani Adaptif, (3) ahli materi, seorang guru yang berkompeten dan berpengalaman dalam bidang olahraga di sekolah. Kedelapan, adalah Revisi yang dilakukan untuk memperbaiki media setelah adanya validasi kepada 3 ahli agar dapat digunakan untuk uji coba. Kesembilan, media siap pakai. Setelah melalui tahap validasi dan revisi, media layak dan siap untuk digunakan dalam uji coba.

Selanjutnya adalah uji coba produk. Uji coba produk memiliki beberapa tahap, yaitu: (1) desain uji coba, meliputi uji coba perseorangan dan uji coba kelompok, (2) subjek uji coba, meliputi seorang siswa down syndrome untuk uji perorangan dan 3 siswa down syndrome untuk uji kelompok, (3) jenis data, data yang digunakan berupa data kualitatif dan kuantitatif, (4) instrumen pengumpul data, menggunakan angket sebagai penilaian lembar validasi para ahli dan tes praktek sebagai penilaian siswa, (5) teknik analisis 
Tabel 1. Analisis hasil evaluasi subjek uji coba kelompok dan perseorangan

\begin{tabular}{cccc}
\hline No. & Persentase & Keterangan & Kriteria \\
\hline 1 & $81 \%-100 \%$ & Sangat tinggi & Sangat efektif \\
2 & $61 \%-80 \%$ & Tinggi & Efektif \\
3 & $41 \%-60 \%$ & Kurang tinggi & Kurang \\
& & & efektif \\
4 & $21 \%-40 \%$ & Rendah & Tidak efektif \\
& & & Sangat tidak \\
5 & $<20 \%$ & Sangat rendah & efektif \\
\hline
\end{tabular}

Tabel 2. Hasil Valiadasi Ahli

\begin{tabular}{|c|c|c|c|}
\hline No & Validator & Presentase & Kriteria \\
\hline 1 & Media & $94 \%$ & $\begin{array}{l}\text { Sangat } \\
\text { layak }\end{array}$ \\
\hline 2 & $\begin{array}{c}\text { Pembelajaran } \\
\text { ABK }\end{array}$ & $92 \%$ & $\begin{array}{l}\text { Sangat } \\
\text { layak }\end{array}$ \\
\hline 3 & Materi & $87 \%$ & $\begin{array}{c}\text { Sangat } \\
\text { layak }\end{array}$ \\
\hline
\end{tabular}

Tabel 3. Data uji coba kelompok

\begin{tabular}{ccccc}
\hline No & Nama & Skor & Presentase & Ketuntasan \\
\hline 1 & $\mathrm{Ar}$ & 73 & $73 \%$ & Tuntas \\
2 & $\mathrm{Ja}$ & 75 & $75 \%$ & Tuntas \\
3 & $\mathrm{Re}$ & 85 & $85 \%$ & Tuntas \\
\hline
\end{tabular}

Terdapat 2 data yaitu data kualitatif dan kuatitatif. Data kualitatif berupa masukan dan saran dari para ahli. Data kuantitatif berupa 2 jenis data yang dianalisa, yaitu analisis validasi produk dan analisis uji coba. Analisis validasi produk menggunakan kriteria skor validasi yang diadaptasi dari Arikunto (2013).

Selanjutnya, terdapat kriteria penilaian yang menjadi acuan mengambil keputusan untuk merevisi produk. Tabel kriteria kualifikasi penilaian validasi produk diadaptasi dari Arikunto dan Jabar (2014).

Analisis data uji coba dilakukan kepada 4 siswa down syndrome. Keefektifan uji coba ditunjukkan berdasarkan ketuntasan pada Standar Ketuntasan Minimal (SKM) yaitu dengan nilai diatas 70 . Presentase ketuntasan subjek uji coba dihitung sesuai rumus yang diadaptasi dari Purwoko (2001). Sedangkan analisis hasil evaluasi subjek uji coba kelompok dan perseorangan ditunjukkan dengan tabel sebagai berikut.

\section{HASIL DAN PEMBAHASAN}

\section{Hasil}

Terdapat pada tabel 2 yaitu hasil validasi dari 3 ahli. Hasil analisis data validasi ahli media menunjukkan 94\% yang berdasarkan kriteria kualifikasi penilaian produk termasuk pada tingkat kriteria sangat layak, yaitu antara skor $81-100$ atau dengan presentase $81 \%$ - $100 \%$. Hasil analisis data validasi ahli pembelajaran ABK menunjukkan 92\% yang berdasarkan kriteria kualifikasi penilaian produk termasuk pada tingkat kriteria sangat layak, yaitu antara skor 81 - 100 atau dengan presentase $81 \%$ - 100\%. Dan hasil analisis data validasi ahli materi menunjukkan $87 \%$ yang berdasarkan kriteria kualifikasi penilaian produk termasuk pada tingkat kriteria sangat layak, yaitu antara skor 81 - 100 atau dengan presentase $81 \%$ $100 \%$.

Hasil uji coba pada perorangan dan kelompok menunjukkan kriteria tuntas. Uji coba perorangan dilakukan kepada seorang siswa dan mendapat nilai 80 dengan presentase ketuntasan $80 \%$, sedangkan uji coba kelompok ditampilkan pada tabel 3.

Hasil uji coba kelompok pada 3 siswa menunjukkan nilai diatas SKM dan menunjukkan kriteria tuntas dan efektif. Berdasarkan hasil validasi dan uji coba produk, video senam ceria sangat layak dan efektif digunakan sebagai media pembelajaran dalam meningkatkan ketrampilan motorik kasar siswa down syndrome.

\section{Pembahasan}

Siswa down syndrome adalah salah satu siswa berkebutuhan khusus yang memiliki hambatan mental, fisik, intelegensi dan kemampuan untuk kontrol motorik. Down Syndrome sangat berpengaruh terhadap tumbuh kembang anak, terutama tumbuh kembang motoriknya (Dekayati et.al , 2014). Anak atau siswa cacat mental ditandai dengan lemahnya kontrol motorik, kurang kemampuannya untuk berkoordinasi, tetapi dipihak lain bisa dilatih untuk mencapai kemampuan sampai ke titik normal (Kusumawati, 2013). Motorik yang dilatih pertama kali adalah motorik kasar. Motorik kasar adalah koordinasi otototot dan saraf yang lebih besar, contohnya berjalan, berlari, merangkak dan makan (Olivia, 2009). Untuk melatih ketrampilan motorik kasar, dapat dilakukan dengan senam. Hasil penelitian yang dilakukan oleh Nisnayeni (2012) menunjukkan bahwa adanya peningkatan perkembangan motorik kasar anak melalui senam irama setelah adanya tindakan pada siklus II. Selain itu terdapat hasil penelitian yang dilakukan oleh (Yusmarni:1) menyimpulkan bahwa dengan kegiatan senam fantasi dapat meningkatkan kemampuan motorik kasar pada anak di Taman Kanak-kanak. Untuk meningkatkan ketrampilan motorik kasar siswa 
down syndrome, dapat dilakukan dengan senam ceria. Senam ceria merupakan adaptasi dari senam irama. senam irama adalah bentuk-bentuk gerakan senam yang merupakan berbagai bentuk gerakan dengan irama yang mengiringinya, misalnya seperti irama tepukan, ketukan, tambore, nyanyian, musik dan sebagainya" (Sudarsini, 2013). Senam ceria dibuat dengan iringan musik dan aba-aba yang memiliki instruktur senam, yaitu seorang badut. Terdapat 3 langkah gerakan dalam senam ceria yaitu gerakan pemanasan, inti dan pendinginan. Pada gerakan pemanasan terdapat gerakan kepala, tangan, melangkah, tepuk tangan dan bersorak. Pada gerakan inti, terdapat gerakan tangan dan kepala, tepuk tangan dan bersorak. Dan pada gerakan pendinginan terdapat gerakan tangan dan kaki. Sebelum memulai senam ceria, terdapat presenter yang akan memandu jalannya video senam ceria. Sebelum senam ceria bersama badut, ditampilkan terlebih dahulu instruktur yang akan memandu setiap gerakan senam dan mengajak anak untuk dapat menirukan dengan pelan. Setelah itu, ditampilkan senam dari awal sampai akhir bersama badut. Senam ceria dilengkapi dengan buku petunjuk yang akan mempermudah guru dalam mempelajari senam ceria.

Hasil analisis data validasi ahli media menunjukkan 94\% yang berdasarkan kriteria kualifikasi penilaian produk termasuk pada tingkat kriteria sangat layak yaitu antara 81-100 atau dengan presentase 81\%$100 \%$. Hal ini menunjukkan bahwa video senam ceria sangat layak digunakan dan mendapat rekomendasi untuk digunakan dilapangan untuk meningkatkan ketrampilan motorik kasar siswa down syndrome. Saran dan masukan dari ahli media berupa : (1) kualitas gambar dipotimalkan, (2) background lebih bagus jika polos, (3) lengkapi dengan petunjuk pemanfaatan, (5) koreo yang atraktif.

Hasil analisis data validasi ahli pembelajaran ABK menunjukkan 92\% yang berdasarkan kriteria kualifikasi penilaian produk termasuk pada tingkat kriteria sangat layak yaitu antara 81-100 atau dengan presentase $81 \%-100 \%$. Hal ini menunjukkan bahwa video senam ceria sangat layak digunakan di lapangan dan menjadi pedoman guru dalam meningkatkan ketrampilan motorik kasar siswa down syndrome. Saran dan masukan dari ahli media pembelajaran ABK adalah pemberian aba-aba yang dilakukan sebelum senam yang diiringi musik dimulai, sehingga selanjutnya siswa dapat menyamakan gerak irama dengan musik.

Hasil analisis data validasi ahli materi menunjukkan $87 \%$ yang berdasarkan kriteria kualifikasi penilaian produk termasuk pada tingkat kriteria sangat layak yaitu antara 81-100 atau dengan presentase $81 \%-100 \%$. Artinya, video senam ceria sangat layak digunakan di lapangan dan menjadi pedoman guru dalam meningkatkan ketrampilan motorik kasar siswa down syndrome.
Hasil uji coba pada perorangan dan kelompok menunjukkan kriteria tuntas. Uji coba perorangan dilakukan kepada seorang siswa dan mendapat nilai 80. Pada uji coba kelompok yang dilakukan pada 3 siswa, keseluruhan mendapatkan nilai diatas SKM dan rerata yang didapatkan adalah 78 .

Dari data hasil uji coba perseorangan dan kelompok, jika dihitung menggunakan rumus (Purwoko, 2001) menunjukkan persentase ketuntasan $100 \%$. Berdasarkan tabel analisis hasil evaluasi subjek uji coba memiliki kriteria sangat efektif, yaitu persentase $81 \%-100 \%$.

Hasil penelitian yang dilakukan oleh Nisnayeni (2012) menunjukkan bahwa adanya peningkatan perkembangan motorik kasar anak melalui senam irama setelah adanya tindakan pada siklus II. Selain itu terdapat hasil penelitian yang dilakukan oleh Yusmarni (2012) menyimpulkan bahwa dengan kegiatan senam fantasi dapat meningkatkan kemampuan motorik kasar pada anak di Taman Kanak-kanak. Demikian pula dengan hasil penelitian dan pengembangan yang berjudul "Pengembangan Video Senam Ceria untuk Meningkatkan Ketrampilan Motorik Kasar Siswa Down Syndrome" menunjukkan bahwa senam ceria layak dan sangat efektif untuk meningkatkan ketrampilan motorik kasar siswa down syndrome.

\section{KESIMPULAN DAN SARAN}

\section{Kesimpulan}

Senam ceria yang dikembangkan sesuai dengan karakteristik siswa down syndrome sebagai media pembelajaran sangat layak dan sangat efektif untuk meningkatkan ketrampilan motorik kasar siswa down syndrome.

\section{Saran}

Diharapkan kepada peneliti dan pengembang selanjutnya untuk lebih kreatif dalam membuat media pembelajaran khususnya untuk mengembangkan hambatan yang dimiliki siswa down syndrome. Subjek penelitian sebaiknya dilakukan pada subjek yang lebih luas baik itu sekolah atau siswa lain yang memiliki hambatan motorik.

\section{DAFTAR RUJUKAN}

Abdurrahman, M. (2012). Anak Berkesulitan Belajar: Teori, Diagnosis dan Remediasinya. Jakarta: Rineka Cipta

Arikunto, S. (2013). Prosedur Penelitian: Suatu Pendekatan Praktik. Jakarta: Rineka Cipta.

Arikunto, S. \& Jabar, C.S.A. (2014). Evaluasi Program Pendidikan: Pedoman Praktis bagi Mahasiswa dan Praktisi Pendidikan. Jakarta: Bumi Aksara. 
Brill, M. T. (2007). Down Syndrome. New York: Marshall Cavendish. Dari Book Google, (Online), (http://books.google.com), diakses 15 Desember 2016.

Dekayati, S., Asih, S. H. M., \& Nurullita, U. (2014). Pengaruh Terapi Bermain Menyusun Menara Donat Terhadap Peningkatan Kemampuan Motorik Anak Down Syndrome Usia Sekolah Di Slb Negeri Semarang. Karya Ilmiah S. 1 Ilmu Keperawatan

Kusumawati, A. (2013). Penanganan Kognitif Anak Down Syndrome Melalui Metode Kartu Warna Di Tk Permata Bunda Surakarta Tahun Ajaran 2013/2014 (Doctoral dissertation, Universitas Muhammadiyah Surakarta).

Mahendra, A. (2007). Sejarah dan pengertian senam.

Nisnayeni. (2012). Peningkatan Perkembangan Motorik Kasar Anak Melalui Senam Irama di Taman Kanak-Kanak Bina Ummat Pesisir Selatan. Jurnal Pesona PAUD, (Online), 1 (1): 1,(http:// download.portalgaruda.org/article.php?article), diakses pada 06 Desember 2016.

Olivia, F. (2009). Kembangkan Kecerdikan Anak dengan Taktik Biosmart. Jakarta: PT Elex Media Komputindo. Dari Book Google, (Online), (http:// books.google.com), diakses 17 Januari 2017.

Pradipta, R. F., \& Andajani, S. J. (2017). Motion Development Program for Parents of Child with Cerebral Palsy. Jurnal Penelitian dan Pengembangan Pendidikan Luar Biasa, 4(2)

Purwoko, A. (2001). Panduan Penelitian PTK. Semarang: Unnes Press.
Sadiman,A,dkk.(2010).MediaPendidikan(Pengertian, Pengembangan dan Pemanfaatannya). Jakarta: Pustekkom Dikbud dan Raja Grafindo Persada.

Santrock, John W. (2007). Child Development, eleventh edition. New York: McGraw Hill Companies Inc.

Sudarsini. (2013). Pendidikan Jasmani dan Olahraga. Malang: Fakultas Ilmu Pendidikan UM.

Undang-Undang Republik Indonesia Nomor 20 Tahun 2003 Tentang Sistem Pendidikan Nasional. Pusat Data dan Informasi Pendidikan. Jakarta: Balitbang Depdiknas. (Online), (http://pendis.kemenag. go.id), diakses 01 Desember 2016.

Yusmarni. (2012). Peningkatan Kemampuan Motorik Kasar Anak Melalui Senam Fantasi Menurut Cerita di Taman Kanak-Kanak Negeri Pembina Padang Pariaman. Jurnal Pesona PAUD, (Online), 1 (1): 1, (http://download.portalgaruda.org/article. php?article), diakses pada 06 Desember 2017 